www.jmscr.igmpublication.org

Index Copernicus Value: 79.54

ISSN (e)-2347-176x ISSN (p) 2455-0450

crossref DOI: https://dx.doi.org/10.18535/jmscr/v7i6.151

Journal Of Medical Science And Clinical Research

IGM Publication

An Official Publication of IGM Publication

\title{
Comparative Analysis of Curve of Spee in Different Malocclusions with Varying Dento-Skeletal Morphological Parameters
}

\author{
Authors \\ Dr Chandrashekhargouda Patil ${ }^{1 *}$ MDS, Dr Tejashwini Patil ${ }^{2}$ BDS, D Ortho \\ Dr P Sunil Kumar ${ }^{3}$ MDS, Dr Reshu Parmar ${ }^{4}$ PG Student, Dr Prashanth $Y^{5}$ MDS \\ Dr Sneha Hoshing ${ }^{6}$ MDS \\ ${ }^{1}$ Professor, ${ }^{2}$ Consultant Orthodontist, ${ }^{3}$ Professor and HOD, ${ }^{4}$ PG Student, ${ }^{4}$ Reader, ${ }^{5}$ Senior Lecturer \\ ${ }^{1,3,4,5,6}$ Department of Orthodontics and Dentofacial Orthopedics, PDU Dental College, Kegaon, Solapur \\ ${ }^{2}$ Consultant Orthodontist and Private Practitioner, Kalaburagi, Karnataka, India \\ *Corresponding Author
}

Dr Chandrashekhargouda Patil MDS

Plot No-44, “Basava Sadan”, Girish Nagar. Bagalkot Road, Near Micro-Wave Station. Vijaypur-586109, Karnataka

\begin{abstract}
Introduction: The influence of craniofacial morphology on the curve of Spee has been investigated, these studies ignore the simultaneous contribution of multiple factors to the individual

variation of the curve. These individual variations play important role in the levelling of the curve which is an everyday occurrence in orthodontic practices and are required for stable results.

Objective: The influence of craniofacial morphology on the variation of the curve of spee includes multiple factors. This plays an important role in the levelling of the curve which is required for retention of achieved results. The study evaluates relationship between the varying depths of curve of spee and dentoskeletal features in malocclusions.

Material and Method: Pre treatment lateral cephalographs and dental casts of 30 orthodontic patients collected and divided into three groups according to different malocclusion. Cephalometric and study cast variables will be measured and subjected to statistical analysis with curve of spee as dependent factor and others as independent variables. Four linear and four angular cephalometric measurements will be done. Four study cast parameters will be measured. Analysis will be performed to determine correlation coefficients between the depth of curve of spee and other variables. Results: lateral cephalograms and study casts were obtained from 30 patients which includes 10 skeletal class I, 10 skeletal Class II and 10 skeletal class III patients. Multiple regression analysis was performed to see the linear dependence of various studied parameters on curve ofSpee. Corresponding beta -coefficient and their 95\% confidence interval (CI) are described. Regression analysis shows that there was no significant correlation between curve of Spee and various parameters. These parameters explained $73 \%$ of the total variation of the curve of Spee.

Conclusion: Following conclusions were drawn on the basis of the findings of this study: The depth of curve of Spee was greatly influenced by sagittal maxillomandibular discrepancies. The variation in the depth of curve of Spee significantly influences the overbite, overjet and the inclination of mandibular first molar. SNA, OM, MD5MP, MD6MP, and $O J$ were negatively correlated and ANB, APDI, ODI, MD6MP, MD7MP, overbite and overjet were positively correlated with depth of curve of Spee for CLASS I SKELETAL. APDI, MD7MP, MD6MP, and OJ were negatively correlated and SNA, ANB, ODI, MD6MP, OM, overbite and overjet were positively correlated with depth of curve of Spee for CLASS II SKELETAL. SNA, ANB, APDI, ODI, OM, MD5MP, MD6MP, OJ and overjet were negatively correlated and MD6MP, MD7MP, and overbite were positively correlated with depth of curve of Spee for CLASS III SKELETAL. The multiple regression analysis showed that the curve of Spee was significantly influenced ODI, overjet and overbite in CLASS I skeletal, overjet and overbite in CLASS II skeletal and only overbite in CLASS III skeletal.

Keywords: craniofacial morphology, Curve of Spee, lateral cephalograms.
\end{abstract}




\section{Introduction}

Occlusal curvature is a naturally occurring phenomenon in the human dentition. Ferdinand Graf Von Spee found in the dentition of other mammals and fossil humans, a line of occlusion, which was termed as curve of Spee and was described in humans in the late 19th century.

Clinically the distal marginal ridges of the posterior teeth in the arch and the incisal edges of the central incisors determine the curve of Spee. ${ }^{1}$

A possible explanation for the development of the curve of Spee is the earlier eruption of mandibular permanent teeth before maxillary counterparts. On average, mandibular first molar erupts 1-2 months earlier than maxillary first molars and eruption of mandibular permanent incisors preceds the maxillary counterparts by 12 months. Due to differential timing of eruption, this could permit the mandibular first molars and incisors to erupt beyond the established occlusal plane. ${ }^{10}$

This implies that the development of curve of Spee is a dental phenomenon. However several factors contribute to the development of curve of Spee including dental eruption timing, craniofacial variation and neuromuscular system. $^{11}$

Curve of Spee has a biomechanical function during food processing by increasing the crushshear ratio between the posterior teeth and the efficiency of Occlusal forces during mastication. ${ }^{2}$

Thieleman introduced the definition of articulation equilibrium $^{12}$ of some morphological factors ( 1 was the

curve of Spee) in a formula:

Articulation equilibrium $=$ Acg $\times$ Aig

Apo $\times$ curve of Spee $\times$ cusp angle

(Acg, angulation of the condylar guidance; Aig, angulation of the incisal guidance; Apo, angulation of the plane of occlusion)

According to his formula, changing the curve of Spee (leveling) influences other factors. ${ }^{12}$

Leveling of the curve of Spee represents a routine procedure in orthodontic practice ${ }^{3}$, and the more pronounced the curve is, the greater the additional space required to flatten the dentition ${ }^{4}$. The assessment of the depth of the curve of Spee is therefore a critical point for the orthodontic diagnostic and treatment protocol ${ }^{5}$.

The influence of craniofacial morphology on the curve of Spee has been systematically investigated in very few studies and with conflicting findings $6,7,8$

Andrew stated that there is a natural tendency for the curve of Spee to deepen with time because the lower jaw's growth downward and forward sometimes is faster and continues longer than that of the upper jaw. This causes the lower anterior teeth, which are confined by the upper anterior teeth and lips, to be forced back and up, resulting in crowded lower anterior teeth and/or a deeper overbite and deeper curve of Spee. ${ }^{9}$

These findings suggested that the curve of Spee might be related to the position and inclination of the upper and lower incisors, lower arch crowding, overjet and overbite.

The proposed research hypothesis is that curve of spee is effected by different craniofacial morphological characteristics in different malocclusions

Therefore the aim of the study is to determine whether curve of spee is effected by different craniofacial morphological characteristics in different malocclusions

\section{Materials and Method}

Lateral cephalograms and plaster models were obtained from 30 patients which includes 10 skeletal class I, 10 skeletal Class II and 10 skeletal class III patients were selected according to following criteria.

1. Patients in the age group of $18-25$ years.

2. No skeletal asymmetry.

3. Full complement teeth up to $2^{\text {nd }}$ molars.

4. Absence of any history of previous orthodontic treatment or surgical treatment.

5. Mild crowding cases were accepted but gross crowding cases were excluded

6. No anterior or lateral cross bite was present. No cast restoration or cuspal coverage was present. 


\section{Exclusion Criteria}

1. Previous orthodontic treatment

2. Unilateral or bilateral posterior cross bite

3. Periodontal disease

4. Posterior dental crowding

5. Morphological tooth anomaly

6. Dental restoration or crown

7. Mandibular asymmetry

8. TMJ dysfunctions

The radiographs were made in standardized conditions with clinical Frankfort horizontal plane kept parallel to the floor, jaws in centric occlusion and lips relaxed using Digital Cephalostat machine Care stream CS 8000c.

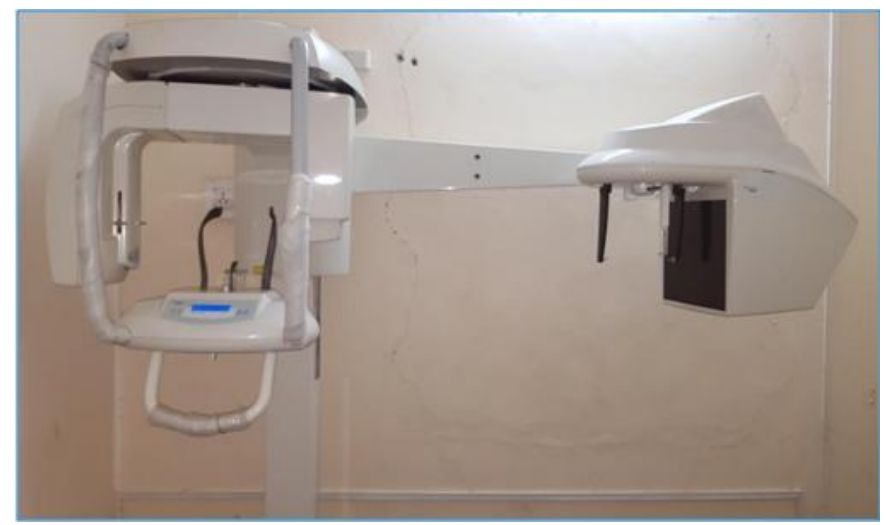

Fig. 1 Digital Cephalostat machine Carestream CS 8000c

This study was conducted in the Department of Orthodontics and Dentofacial Orthopedics, P.D.U. Dental College, Solapur, Maharashtra, India. Tracing was done on acetate matte tracing paper (0.003" thick; 8X10") using $0.3 \mathrm{~mm}$ tip pencil. A single operator performed all the tracings in standardized manner to avoid errors due to inter operator variations. Angular measurements were made to $0.5^{0}$.

\section{Measurement of Curve of Spee on Study Cast}

The depth of curve of Spee was measured as the perpendicular distance between the deepest buccal cusp tips and a scale that was laid on the top of the mandibular dental cast, touching the incisal edges of the central incisors and the distal cusp tips of the most posterior teeth in the lower arch (Fig. OF CURVE OF SPEE).
The depth of curve of Spee was measured with divider placed between the deepest cusp tip and the scale. The measurements was made on the right and left side of the mandibular cast and the mean value of these two measurements was used as the depth of curve of Spee. ${ }^{12}$

The cephalometric and study cast measurements used in the study are described in table. The four skeletal parameters, six dentoalveolar parameters and three study cast parameters were measured The following landmarks were marked on the lateral cephalogram (Table no 1)

\begin{tabular}{|l|c|}
\hline \multicolumn{1}{|c|}{ S.NO } & PARAMETER \\
\hline Skeletal horizontal \\
\hline 1. & SNB (degree \\
\hline 2. & ANB (degree) \\
\hline 3. & APDI (degree) \\
\hline Skeletal vertical & ODI (degree) \\
\hline 4. & Md6 to MP (degree) \\
\hline Dentoalveolar horizontal \\
\hline 5. & Md7 to MP (degree) \\
\hline 6. & OM (mm) \\
\hline 7. & Md5 to MP (mm) \\
\hline Dentoalveolar vertical \\
\hline 8. & Md6 to MP (mm) \\
\hline 9. & OJ (mm) \\
\hline 10. & Overbite (mm) \\
\hline Study cast & Overjet (mm) \\
\hline 11. & Curve of spee \\
\hline 12. &
\end{tabular}

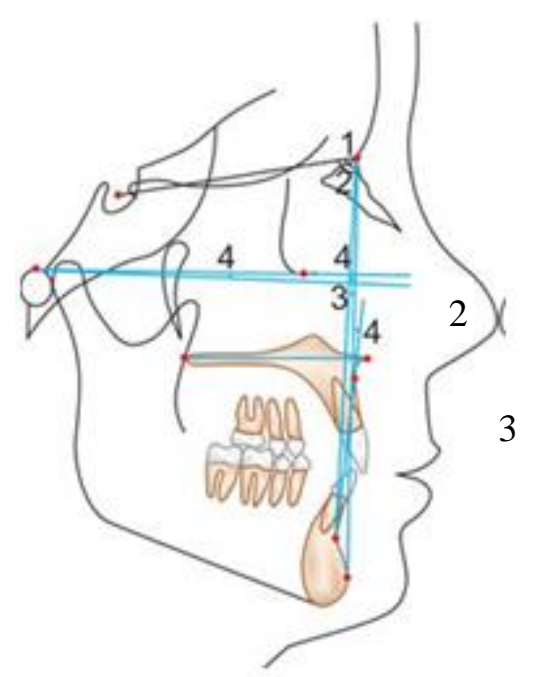

Skeletal Horizontal Parameters

1) SNA

2) ANB

3) APDI-Facial plane angle $+\mathrm{AB}$ plane angle + Palatal plane angle 


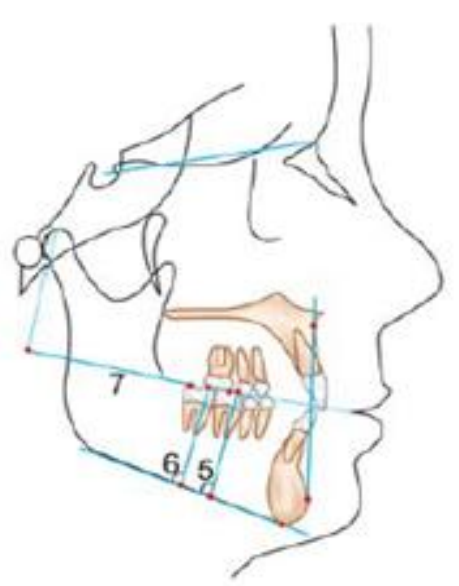

Dentoalveolar Horizontal Parameter

4)Md $6 \mathrm{Mp}$

5) $\mathrm{Md} 7 \mathrm{Mp}$

6) $\mathrm{OM}(\mathrm{mm})$

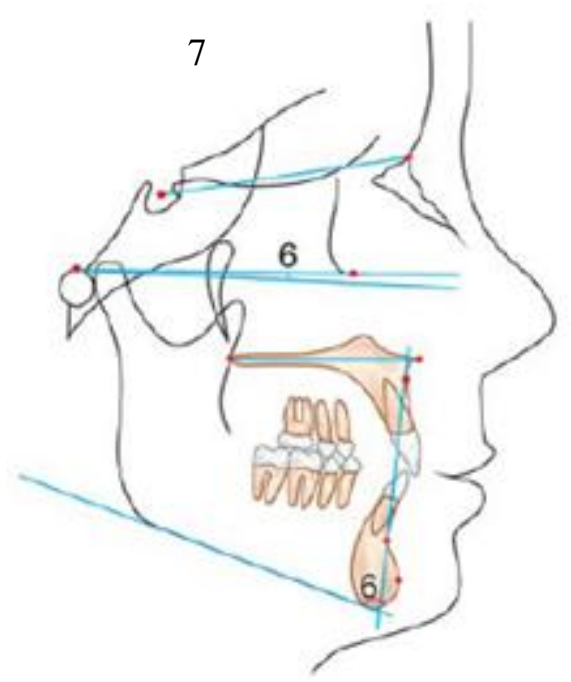

Skeletal Vertical Parameters

7) ODI-AB Plane angle to mandibular plane angle + + palatal plane angle

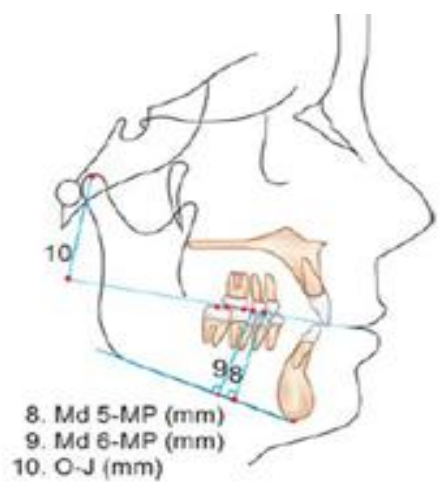

Dentoalveolar Vertical Parameter

8)Md 5-Mp(mm)

9)Md 6-Mp(mm)

10)OJ (mm)

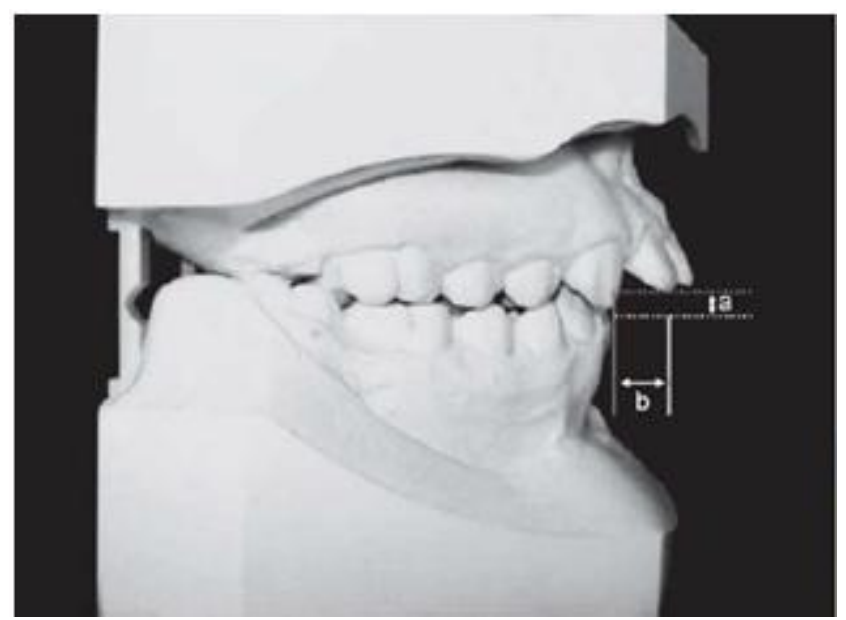

a)overbite

b)overjet

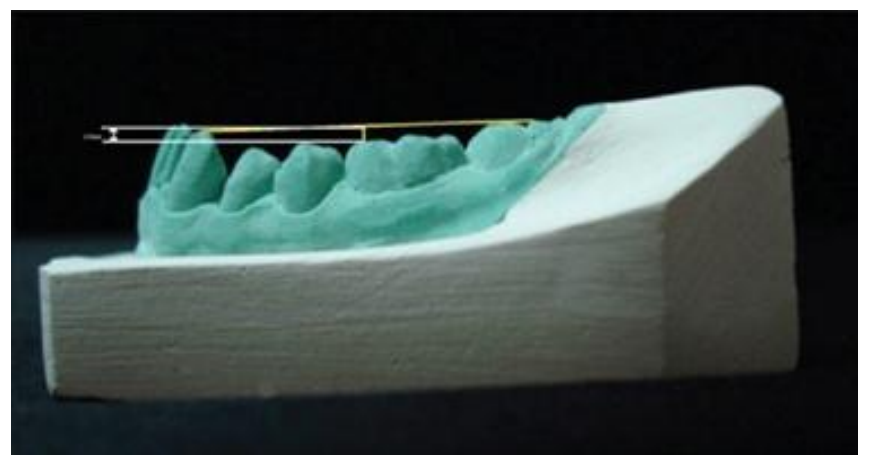

Measurement of curve of spee

\section{Statistical analysis}

The data were tabulated and analyzed by statistical software SPSS v 16.0. The descriptive statistics such as mean, mean differences, standard deviations and standard errors were calculated for all variables. The paired $\mathrm{t}$ test was used to compare the variables within the groups. One-way analysis of variance (ANOVA; F statistics) was used for comparing the measurements for Class-I, Class-II and Class-III in both groups. Correlations between variables were done by using Pearson's correlation coefficient. Significance was determined at the 0.05 and 0.01 levels of significance. Regression equation were set for the significant correlations.

\section{Results}

Lateral cephalograms and study casts were obtained from 30 patients which includes 10 skeletal class I, 10 skeletal Class II and 10 skeletal class III patients. 
Table 2: Comparison of various parameters between classes

\begin{tabular}{|l|c|c|c|}
\hline & & & \\
\hline & $\begin{array}{c}\text { CLASS I } \\
\text { SKELETAL }\end{array}$ & $\begin{array}{c}\text { CLASS II } \\
\text { SKELETAL }\end{array}$ & $\begin{array}{c}\text { CLASS III } \\
\text { SKELETAL }\end{array}$ \\
\hline SNA & $81.33 \pm 4.2$ & $82.9 \pm 3.9$ & $79.1 \pm 7.3$ \\
\hline ANB & $1.9 \pm 0.3$ & $4.5 \pm 2.5$ & $-3.0 \pm 2.3$ \\
\hline APDI & $92.7 \pm 5.3$ & $92.8 \pm 7.5$ & $90.1 \pm 6.9$ \\
\hline ODI & $78.2 \pm 6.8$ & $80.0 \pm 4.6$ & $69.3 \pm 6.4$ \\
\hline MD6MP & $83.8 \pm 6.4$ & $80.4 \pm 7.1$ & $81.4 \pm 8.3$ \\
\hline MD7MP & $89.7 \pm 6.5$ & $84.9 \pm 5.1$ & $84.4 \pm 5.6$ \\
\hline OM & $38.0 \pm 5.3$ & $37.4 \pm 3.9$ & $39.1 \pm 6.0$ \\
\hline MD5MP & $27.4 \pm 2.6$ & $28.1 \pm 2.7$ & $28.7 \pm 3.1$ \\
\hline MD6MP & $26.1 \pm 2.4$ & $26.8 \pm 2.4$ & $26.7 \pm 2.8$ \\
\hline OJ & $26.9 \pm 2.3$ & $26.7 \pm 6.6$ & $29.4 \pm 6.1$ \\
\hline Overjet & $4.1 \pm 3.2$ & $4.9 \pm 3.1$ & $0.6 \pm 2.82$ \\
\hline Overbite & $1.8 \pm 2.4$ & $4.2 \pm 2.3$ & $3.2 \pm 2.6$ \\
\hline
\end{tabular}

There was significant difference between classes for ANB, ODI and overjet.

Table 3: Correlation between curve of spee with different parameters

\begin{tabular}{|l|c|c|c|c|c|c|}
\hline & \multicolumn{2}{|c|}{ CLASS I SKELETAL } & \multicolumn{2}{c|}{ CLASS II SKELETAL } & \multicolumn{2}{c|}{ CLASS III SKELETAL } \\
\hline Parameters & r-value & p-value & r-value & p-value & r-value & p-value \\
\hline SNA & -0.23 & 0.54 & 0.16 & 0.68 & -0.17 & 0.68 \\
\hline ANB & 0.45 & 0.22 & 0.28 & 0.46 & -0.20 & 0.63 \\
\hline APDI & 0.14 & 0.72 & -0.02 & 0.96 & -0.17 & 0.68 \\
\hline ODI & 0.82 & 0.007 & 0.31 & 0.42 & -0.10 & 0.81 \\
\hline MD6MP & 0.38 & 0.32 & 0.07 & 0.85 & 0.21 & 0.62 \\
\hline MD7MP & 0.25 & 0.51 & -0.45 & 0.23 & 0.43 & 0.28 \\
\hline OM & -0.27 & 0.48 & 0.31 & 0.42 & -0.30 & 0.47 \\
\hline MD5MP & -0.51 & 0.16 & -0.05 & 0.89 & -0.37 & 0.36 \\
\hline MD6MP & -0.61 & 0.08 & -0.16 & 0.67 & -0.39 & 0.34 \\
\hline OJ & -0.33 & 0.38 & -0.44 & 0.24 & -0.005 & 0.99 \\
\hline Overjet & 0.76 & 0.02 & 0.73 & 0.02 & -0.49 & 0.21 \\
\hline Overbite & 0.68 & 0.04 & 0.74 & 0.02 & 0.78 & 0.02 \\
\hline
\end{tabular}

p-value: $<0.05-\#,<0.01-*,<0.001-* *$

The correlation table shows SNA, OM, MD5MP, MD6MP, and OJ were negatively correlated and ANB, APDI, ODI, MD6MP, MD7MP, overbite and overjet were positively correlated with depth of curve of Spee. But statistically significant correlation found between ODI $(\mathrm{p}=0.007)$, Overjet $(\mathrm{p}=0.02)$ and Overbite $(\mathrm{p}=0.04)$ with curve of Spee for CLASS I SKELETAL.

The correlation table shows APDI, MD7MP, MD6MP, and OJ were negatively correlated and SNA, ANB, ODI, MD6MP, OM, overbite and overjet were positively correlated with depth of curve of Spee.

But statistically significant correlation found between Overjet $(\mathrm{p}=0.02)$ and Overbite $(\mathrm{p}=0.02)$ with curve of Spee for CLASS II SKELETAL. The correlation table shows SNA, ANB, APDI, ODI, OM, MD5MP, MD6MP, OJ and overjet were negatively correlated and MD6MP, MD7MP, and overbite were positively correlated with depth of curve of Spee. But statistically significant correlation found only between Overbite $(\mathrm{p}=0.02)$ with curve of Spee for CLASS III SKELETAL.

Table-4: Multiple regression analysis - CLASS I SKELETAL

\begin{tabular}{|c|c|c|c|}
\hline Parameters & $\begin{array}{c}\text { Beta-coefficient } \\
(95 \% \mathrm{CI})\end{array}$ & $\begin{array}{c}\mathrm{p}- \\
\text { value }\end{array}$ & $\begin{array}{c}\mathrm{R}^{2} \\
\text { change }\end{array}$ \\
\hline ODI & $0.068(-0.04-0.17)$ & 0.16 & \multirow{4}{*}{0.73} \\
\hline Overjet & $0.09(-0.26-0.45)$ & 0.54 & \\
\hline Overbite & $0.003(-0.43-0.43)$ & 0.98 & \\
\hline Constant & $-3.69(-11.3-3.93)$ & 0.27 & \\
\hline
\end{tabular}

Multiple regression analysis was performed to see the linear dependence of various studied parameters on curve of Spee. Corresponding beta -coefficient and their 95\% confidence interval 
(CI) are described in Table 4.Regression analysis shows that there was no significant correlation between curve of Spee and various parameters. These parameters explained $73 \%$ of the total variation of the curve of Spee.

Table-5: Multiple regression analysis - CLASS II SKELETAL

\begin{tabular}{|l|c|c|c|}
\hline Parameters & $\begin{array}{c}\text { Beta-coefficient } \\
(95 \% \text { CI })\end{array}$ & p-value & \multirow{2}{*}{$\mathrm{R}^{2}$ change } \\
\hline Overjet & $0.088(-0.29-0.47)$ & 0.59 & \multirow{2}{*}{0.57} \\
\hline Overbite & $0.13(-0.39-0.65)$ & 0.57 & \\
\hline Constant & $1.36(0.36-2.37)$ & 0.02 & \\
\hline
\end{tabular}

Multiple regression analysis was performed to see the linear dependence of various studied parameters on curve of Spee. Corresponding beta -coefficient and their 95\% confidence interval (CI) are described in Table 5.Regression analysis shows that there was no significant correlation between curve of Spee and various parameters, These parameters explained $57 \%$ of the total variation of the curve of Spee.

Table-6: Multiple regression analysis - CLASS III SKELETAL

\begin{tabular}{|l|c|c|c|}
\hline Parameters & $\begin{array}{c}\text { Beta-coefficient } \\
(95 \% \mathrm{CI})\end{array}$ & $\mathrm{p}$-value & $\begin{array}{c}\mathrm{R}^{2} \\
\text { change }\end{array}$ \\
\hline Overbite & $0.27(0.06-0.49)$ & 0.02 & \multirow{2}{*}{0.61} \\
\hline Constant & $1.18(0.30-2.06)$ & 0.017 & \\
\hline
\end{tabular}

Multiple regression analysis was performed to see the linear dependence of various studied parameters on curve of Spee. Corresponding beta -coefficient and their 95\% confidence interval (CI) are described in Table 6 .Regression analysis shows that there was significant correlation between curve of Spee and overbite $(p=0.02)$. These parameters explained $61 \%$ of the total variation of the curve of Spee.

\section{Discussion}

The assessment of relationship of curve of Spee with the dentoskeletal morphology is essential to understand the influence of multiple factors that leads to variation in the depth of the curve. It has been suggested that the mandibular sagittal and vertical position relative to the cranium is related to the curve of Spee, which is present in various forms in mammals (Farella et al) ${ }^{14}$
In humans, an increased curve of Spee is often seen in brachycephalic facial patterns (Wylie ${ }^{15}$ and Bjork $^{16}$ ) and associated with short mandibular bodies (Salem $\mathrm{OH}$ et al) ${ }^{17}$

The measurement of curve of Spee was done and the average of the distance on right and left side was taken as the depth of curve of Spee (Nanda SK, ${ }^{18}$ Dale $\mathrm{J}^{19}$ ) This method of assessment of curve of Spee was easy to perform and lacked any magnificational and projectional errors.

The age group was in the range of 18 to 25 years to omit any effect of growth on the curve of Spee since, the depth remained relatively constant during adulthood as compared to the flat curve in decidous dentition and maximum deepening during adolescent dentition (Marshall et al) ${ }^{20}$

It was found that the subjects with higher maxillomandibular discrepancies tend to have deeper curve of Spee. The value of ANB showed positive correlation with the depth of curve of Spee, i.e. was less in subjects with small value of ANB angle (suggesting Class I skeletal pattern) and as the value of ANB angle increased the depth of curve of Spee also increased (the Class-II skeletal pattern) also supported by Cheon et $\mathrm{al}^{21}$ and Orthlieb JD ${ }^{22}$ who suggested that the depth of curve of Spee was lesser in those with Class III malocclusions than in Class II malocclusions.

The curve of Spee was influenced by the skeletal pattern of the subjects as suggested by the values of APDI, that is smaller the APDI value in relation to the normal mean greater was the probability of distocclusion thus suggesting Class II skeletal pattern and deep curve of Spee. This finding was similar to a study conducted by Cheon et al ${ }^{21}$

Overbite depth indicator was given by $\mathrm{Kim}^{23}$ suggesting that lower the ODI value greater the chance of there being open bite or tendency toward an open bite. The overbite and tendency toward deep bite were found to increase as the ODI value increased.

In the present study the findings suggested that as the depth of curve of Spee increases from Groups I 
to II the tendency for deep bite in the subjects also increases and decreases in group III

The positive correlation value in group I and group II suggested that the value of ODI increases with increase in the depth of curve of Spee.

Md6 to MP and Md7 to MP angles were considered to asses the possible relation between the axial inclination of the mandibular molars and the depth of curve of Spee. The mean values were found to be decreased with increase in curve of Spee depth suggesting that the mesial inclination of the molars were increasing as the depth of the curve of Spee was increased .These findings were also reported by Shannon and Nanda ${ }^{24}$ and Lie $F^{25}$ who suggested that deepening of curve of Spee can occur as the axial inclination of the teeth increases.

OM (mm) was the distance measured from the most posterior point of the dentition on the occlusal plane (point ' $M$ ') to the point of intersection (point ' $\mathrm{O}$ ') of a line perpendicular from the superior most point on the condyle (Farella et al) ${ }^{14}$ It is the linear distance signifying the horizontal positioning of the dentition with respect to the condyle

The value of OM (mm) was found to be decreasing from Groups I to II suggesting that the samples in which the dentition was more posteriorly positioned with respect to the condyle, and increased in group III suggesting dention was positioned anteriorly with respect to condyle.

The difference of the mean value for Md5 to MP $(\mathrm{mm})$ showed nonsignificant correlations. it was increased in group I and group II with respect to group I due to greater infra position of the mandibular second premolar with relation to mandibular. In the present study the deepest point of the curve of Spee was found to be the cusp tip of second premolar region in maximum

number of samples. Koyama ${ }^{26}$ and Lie $\mathrm{F}^{25}$ also supported this finding and suggested that the deepest point of the curve is the cusp tip of mandibular second premolar. There is lack of significant difference between the depth of curve of Spee and perpendicular distance of mandibular plane to the molar cusp tip same was found in this study.

OJ signifies the vertical positioning of the lower dentition with respect to the condyle. It was measured as the perpendicular distance between the superior most point on the condylar head (point ' $\mathrm{J}$ ') and the point of intersection of this perpendicular to the occlusal plane (point ' $\mathrm{O}$ ') ${ }^{14}$. It is found to be increased in group III compared to group I and group II .This finding suggested that the dentition had moved downward with respect to the condyle in group III.

The mean value for overbite and overjet was found to be increased in group II. This suggested that when the anterior teeth have no vertical stop, their continued eruption leads to deepening of anterior aspect of the curve. This was supported by findings of Shannon and Nanda. ${ }^{24}$ The positive correlation coefficient value also proved as the overbite increases depth of curve of Spee also increases.

These findings were supported by studies done by Lie F. ${ }^{25}$

The statistically significant beta-correlation coefficients between the depth of curve of Spee and overbite confirmed this result

The purpose of this cross-sectional study was to find out the correlation between the dentoskeletal morphology and the depth of curve of Spee. This study has unmasked the dentoskeletal morphologic features associated with different malocclusions

Subjects with deep curve of Spee had shown to have sagittal discrepancies, posteriorly and superiorly positioned dentition in the mandible suggesting Class II pattern. Dentally these subjects showed deep overbites, elevated anterior teeth, depressed premolars and mesially inclined molars.

\section{Conclusion}

Following conclusions were drawn on the basis of the findings of this study:

1) The depth of curve of Spee was greatly influenced by sagittal maxillomandibular 
discrepancies. The values for parameters ANB and APDI suggested that the mandible was located more posteriorly in deep curve of Spee .

2) The variation in the depth of curve of Spee significantly influences the overbite, overjet and the inclination of mandibular first molar.

3) SNA, OM, MD5MP, MD6MP, and OJ were negatively correlated and ANB, APDI, ODI, MD6MP, MD7MP, overbite and overjet were positively correlated with depth of curve of Spee for CLASS I SKELETAL.

4) APDI, MD7MP, MD6MP, and OJ were negatively correlated and SNA, ANB, ODI, MD6MP, OM, overbite and overjet were positively correlated with depth of curve of Spee for CLASS II SKELETAL.

5) SNA, ANB, APDI, ODI, OM, MD5MP, MD6MP, OJ and overjet were negatively correlated and MD6MP, MD7MP, and overbite were positively correlated with depth of curve of Spee for CLASS III SKELETAL.

6) The multiple regression analysis showed that the curve of Spee was significantly influenced ODI, overjet and overbite in CLASS I skeletal, overjet and overbite in CLASS II skeletal and only overbite in CLASS III skeletal.

\section{References}

1. No author listed. The gliding path of the mandible along the skull. Ferdinand Graf Spee (1855-1937), Prosector at the Anatomy Institute of Krel. J Am DentAssoc 1980; 100: 670-5.

2. Osborn JW. Relationship between the mandibular condyle and the occlusal plane during hominid evolution: some of its effects on jaw mechanics. Am J Phys Anthropol 1987; 73: 193-207.

3. Tweed $\mathrm{CH}$. Clinical orthodontics. St Louis: CV Mosby, 1966.
4. Braun S, Hnat WP, Johnson BE. The curve of Spee revisited. Am J Orthod Dentofacial Orthop 1996; 110: 206-210.

5. Germane N, Staggers JA, Rubenstein L, Revere JT. Arch length considerations due to the curve of Spee: a mathematical model. Am J Orthod Dentofacial Orthop 1992; 102: 251-255.

6. Orthlieb JD, Slaviceck R. Geometrische interpretation der Spee kurve. Z Stomatologie 1985; 82: 1-18.

7. Ghezzi F, Drago E, De Thomatis P, Zallio F. Profondita`della curva di Spee in rapporto a FMA, FH, ANB e classe dentale. Mondo Ortodontico 1991; 1: 7376.

8. Orthlieb JD. The curve of Spee: understanding the sagittal organization of mandibular teeth. Cranio 1997; 15: 333340.

9. Andrews LF. The six keys to normal occlusion. Am J Orthod. 1972;62:296309.

10. Veli I, Ozturk MA, Uysal T. Curve of spee and its relationship to vertical eruption of teeth among different malocclusion groups. Am J Orthod Dentofacial Orthop 2015; 147(3):305-12.

11. Dhiman S. Curve of Spee - from orthodontic perspective. Indian J Dent 2015; 6(4):199-202.

12. Naeije M, Van Loon LAJ. Craniomandibulaire functie en dysfunctie. Houten: Bohn Stafleu Van Loghum; 1998.

13. Baydas B, Yavuz I, Atasarl N, Ceylan T, Dagsuyu I. Investigationof the changes in the positions of upper and lower incisors, overjet, overbite and irregularity index in subjects with different depths of curve of Spee. Angle Orthod 2004;74:349-55.

14. Farella M, Michelotti A, van Eijden TMG, Martina R. The curve of Spee and craniofacial morphology: A multiple regression analysis European $\mathrm{J}$ Oral Sciences 2002;110:277-81. 
15. Wylie WL. Overbite and vertical facial dimensions in terms of muscle balance. Angle orthod 1944;14:13-27.

16. Bjork A. Variability and age changes in overjet and overbite. Am J Orthod 1953;39:779-801.

17. Salem OH, Al-Sehaibany F, Preston CB. Aspects of mandibular morphology, with specific reference to the antegonial notch and the curve of Spee. J Clin Pediar Dent 2003;27:261-65.

18. Nanda Surinder K. The developmental basis of occlusion and malocclusion. Chicago Quintessence Publishing Company 1983;244-58.

19. Dale Jack G. Guidance of occlusion: Serial extraction. Chapter 5, ln: Graber TM and Swain BF (Eds), Orthodontics current principles and techniques, St Louis, The CV Mosby Company 1985;pp 303.

20. Marshall SD, Caspersen M, Hardinger RR. Franciscus RG, Aquilino SA, Southard TE. Development of the curve of Spee. Am J Orthod Dentofacial Orthop 2008;134:344-52.

21. Cheon S, Park Y, Paik K, Ahn S, Hayashi K, Yi W, Lee S. Relationship between the curve of Spee and dentofacial morphology evaluated with a 3-dimensional reconstruction method in Korean adults. Am J Orthod Dentofacial Orthop 2008;133:640:e7-14

22. Orthlieb JD. The curve of Spee: Understanding the sagittal organization of mandibular teeth. Cranio 1997;15:333-40.

23. Kim YH. Overbite depth indicator with particular reference to anterior openbite. Am J Orthod 1974;65:586-611.

24. Shannon KR, Nanda R. Changes in the curve of Spee with treatment and at years post-treatment. Am J Orthod Dentofacial Orthop 2004;125:589-96.
25. Lie F, Kuitert R, Zenter A. Post-treatment development of the curve of Spee. Eu J Orthod 2006;28:262-68.

26. Koyama TA. Comparative analysis of the curve of Spee (lateral aspect) before and after orthodontic treatment with particular reference to overbite patients. J Nihon Univ Sch Dent 1979;21:25-34. 